\title{
Arquitetura da formação contínua docente: \\ das práticas pedagógicas aos saberes e experiências ${ }^{1}$ \\ Architecture of continued teacher training: \\ from pedagogical praxis to backgrounds and experiences
}

\author{
Osmar Hélio Alves Araújo² \\ osmar.araujo@urca.br
}

\begin{abstract}
Resumo
Este ensaio busca levantar os pilares para a construção de um processo de formação contínua docente coerente com a arena escolar. Trata-se de delinear a arquitetura da formação contínua docente e, por conseguinte, contribuir na (re)construção da educação de aurora, pois se compreende que a formação contínua do professor é um vetor interveniente no futuro da educação. Em suma, a discussão em tela aborda a construção da formação contínua do docente no contexto escolar.
\end{abstract}

Palavras-chave: Coordenação pedagógica, Formação docente, Arena escolar

\begin{abstract}
This paper aims to focus on the pillars for building a coherent continued teacher training process along with school arena. It is about outlining the architecture of continued teacher training and, therefore, to contribute for the (re)construction of a new education, since the continued teacher training is understood as a fundamental element for the future of education. In brief, the discussion to be followed throws lights on the basis of the continued teacher training on schooling context.
\end{abstract}

Keywords: Pedagogical coordination, Teacher training, Schooling arena.

\footnotetext{
1 Este texto teve como solo embrionário a primeira aula (semestre 2015.2) da disciplina Seminário temático II, Educação, Memória, Sociedade e Patrimônio, do Programa de PósGraduação em Educação, Universidade Federal do Ceará - UFC, sob a coordenação do professor dr. Luís Távora Furtado Ribeiro, prof. dr. Raimundo Elmo e do prof. dr. Romeu Duarte Júnior. O autor agradece aos professores pelas contribuições na concepção deste texto.

2 Licenciado em Letras, especialista em Supervisão e Orientação Educacional e mestre em Educação pela Faculdade de Educação da Universidade Federal do Ceará (UFC). Atualmente, integra o Grupo de Pesquisas em Formação Docente, História e Política Educacional da Universidade Federal do Ceará (UFC). Professor temporário da Universidade Regional do Cariri - Urca; professor-formador do Parfor na Universidade Estadual Vale do Acaraú -UVA e docente colaborador da Pós-Graduação Lato Sensu das Faculdades Inta.
} 


\section{Ideias Introdutórias}

Entre as intenções deste corpo teórico, encontra-se a assertiva de assentar a escola, arena permeada por experiências, como o campo eficaz no que concerne à formação contínua do professor, compreendida aqui como uma das ações pedagógicas inerente ao trabalho do coordenador pedagógico. Desse modo, doravante, discorrer a respeito do coordenador pedagógico em interface com a arquitetura da formação contínua docente, é o objetivo desta discussão. Por consequência, espera-se contribuir para o processo de suplantação de todo o processo de formação docente, que não se sustenta apenas no solo escolar, saberes e práticas docentes, entre outros elementos. Nesse sentido, assinala-se, a princípio, que as práticas pedagógicas, saberes e experiências dos professores se constituem em pilares para a construção de um processo de formação contínua docente, coerente com a arena escolar.

\section{Entrelaçando as ideias, materializando a discussão}

A priori, cabe sublinhar a necessidade da construção de um processo de formação docente centrado no contexto escolar. Assim, ousa-se aqui apresentar os pilares que, em geral, devem contribuir para a arquitetura da boa formação contínua docente.

Decerto, uma formação docente sob medida para cada escola depende, necessariamente, das práticas pedagógicas, saberes e experiências dos professores. Por isso, exercer a função de coordenador pedagógico é pensar em formação docente sempre, e, assim, a formação contínua do professor deve estar sempre em processo, isto é, à procura de vias novas para a transformação das práticas pedagógicas dos professores. Porém, perceber a necessidade da formação contínua do professor e querer executá-la é a metade do caminho. A outra metade é, de fato, encontrar trilhas para a formação ser colocada em prática.

Nessa perspectiva, cabe sublinhar o papel do coordenador no processo de formação do professor no espaço escolar, enquanto lócus fecundo para a qualificação profissional docente, isto é, leva-se a cabo a função formativa do referido profissional e o contexto escolar como arena formativa dos professores. Destarte, a escola é um espaço de formação, reflexão e 
ressignificação da prática pedagógica. Entretanto, Clementi (2005) traz a lume que o desconhecimento do que vem a ser a formação dos professores, bem como dos elementos correlatos à construção e vivência do projeto pedagógico são componentes de interdição na atuação do coordenador.

No tocante ao papel de assegurar aos professores um espaço de formação, Garcia (2007) atribui ao coordenador pedagógico a função de viabilizar aos professores um espaço de formação, a partir do qual eles possam explicitar os estorvos e dúvidas, e como um contexto que possibilite o acesso a uma teoria, enquanto elemento necessário para aperfeiçoamento e robustecimento da sua dignidade profissional.

Aqui, parte-se do pressuposto que, para a construção de um edifício, de uma casa ou qualquer outra obra, faz-se necessário um projeto e uma planta, traçada por um engenheiro civil. Do mesmo modo, para adornar e assegurar as suas características viscerais, é essencial um projeto arquitetônico. Com isso, o arquiteto lança seu poder criador, isto é, sua inventividade, capacidade criadora de atribuir vida e beleza à obra. Do mesmo modo, os professores são verdadeiros arquitetos, pois trazem, cada um ao seu modo, o poder de criar, transformar e de fazer diferente o trabalho pedagógico.

O professor, nesse contexto, deve participar da construção e desenvolvimento da sua própria formação. Para isso, o processo de formação contínua do professor deve possuir como alicerce o protagonismo docente para a construção e corporificação do aludido processo. A adoção dessa pedra angular é um princípio que assegura a sedimentação de uma formação com e para os professores, visto que eles têm um papel indispensável no formar/autoformar-se. A partir daí, devem permanecer, portanto, devolutos de coerções e de qualquer tipo de exclusão do seu próprio processo de formação, pois, muitas vezes, a liberdade para produzir e veicular saberes e experiências são dificultadas. A intercorrência na efetivação dos ditames legais que asseguram o acesso às possibilidades de produção do conhecimento assume solo embrionário do descontentamento de parte da classe do magistério, que se mobiliza para ver seus direitos constitucionais respeitados e assegurados.

Verifica-se, contudo, que os professores devem participar dos debates, das atividades e das políticas públicas do país que tratam da sua formação, 
não somente para enriquecê-las à luz dos saberes docentes, princípios teóricos e éticos da profissão, mas também para defender seu direito nativo de um permanente processo de formação, que exige, entre outros elementos, profissionais qualificados para mediá-lo, condições salariais, inclusão do referido processo na carga horária de trabalho e respeito aos saberes emergidos da prática pedagógica. Entende-se, desde já, que as experiências e saberes docentes são plurais e diversos, assegurando, então, a todos os professores, a prerrogativa de contribuir para a elaboração das atividades a eles relacionadas.

Sugere-se, portanto, aos profissionais responsáveis pela concretização da formação contínua do docente, dentre eles, o coordenador pedagógico, uma incumbência outorgada por ditames oficiais, a velar ao que determina a legislação em relação ao cumprimento do referido processo. Diante de dúvidas, irregularidades e da não efetivação do processo formativo permanente, cabe aos professores manterem-se vigilantes, para que os órgãos competentes cumpram o que determina os termos da outorga constitucional (BRASIL, 2005, 2014). Com isso, que a classe do magistério se entrincheire com argumentos para se contrapor a eventuais práticas, que pretendem desqualificar o papel do professor no âmbito da construção de propostas formativas para os docentes, políticas públicas relativas a uma educação de qualidade, digna. Em suma, é imprescindível que os professores sejam reconhecidos pela excelência do seu exercício educacional.

A escola precisa promover, sistematicamente, para os professores, uma formação que: 1) viabilize a compreensão dos fundamentos teóricos correlatos à construção de uma educação progressista, libertadora, emancipatória; e 2) contribua para plantar uma prática pedagógica abrangente, multidisciplinar e conectada ao contexto contemporâneo. No tocante aos objetivos da formação supramencionada, deve pautar-se na construção e disseminação de conhecimentos que suscitem transformações no processo educativo, interligando-o aos artefatos tecnológicos, assim como favorecendo a construção de práticas pedagógicas tempestivas às necessidades do sujeito contemporâneo. Além do mais, deve-se perseguir como metas: a) colocar em marcha uma formação abalizada em um processo dialógico; b) propiciar 
ensejos de avaliação, análises das práticas pedagógicas, diante da sociedade, em tempo de mudanças; 3) promover uma formação que estimule o uso adequado do conhecimento, por meio de uma prática pedagógica, em uma perspectiva emancipatória, libertária, visando ao crescimento do homem e à educação como direito humano.

Uma formação contínua para o docente, tendo como solo embrionário um processo dialógico, exige, necessariamente, ter como tecido base a própria prática pedagógica do professor. Desse modo, o referido processo deve robustecer o diálogo com os professores, a partir do seu próprio fazer, ao invés de cultivar práticas impositivas, comuns em arenas que não se pautam em uma perspectiva democrática. Uma formação abalizada por princípios dialógicos necessita de fundamentos teóricos e práticas interligadas aos paradigmas da gestão democrática para, então, garantir a socialização de experiências consumatórias que confluirão para o surgimento de novos saberes. Sendo assim, o coordenador pedagógico deve ser capaz de gerar um ambiente favorável à troca de experiências, ao diálogo.

No que tange a momentos de avaliação, revisão das práticas pedagógicas em interface com a sociedade permeada por mudanças, faz-se necessário, a priori, análises dos conteúdos e temas que norteiam os encontros de formação, ou seja, a qualidade daquilo que é oferecido aos professores, bem como das implicações dos mesmos na reconstrução das práticas pedagógicas. Recomenda-se, contudo, uma metodologia que abarque, entre outros procedimentos, o estudo de casos específicos, que privilegie a análise de situações, projetos, ações pedagógicas vivenciadas no cerne da escola. A meta deve ser permitir aos professores, por meio da análise de casos específicos, conhecer as práticas pedagógicas materializadas no âmago da escola; correlacioná-las aos princípios que norteiam o projeto político pedagógico; identificar as fragilidades que exigem serem reconstruídas, assim como idear uma nova prática pedagógica, isto é, transformar o velho(?) em novo.

Em relação à promoção de uma formação que incentive o uso adequado do conhecimento por meio de uma prática pedagógica que o plante em um prisma emancipatório, libertário, visando ao crescimento do homem e à 
educação como direito humano, parte-se aqui do pressuposto que, se, de um lado, a sociedade contemporânea é aclamada como a sociedade do conhecimento, em decorrência da proliferação dos recursos tecnológicos que difundem informações das mais diversas estirpes, tal situação exige cuidados, dada a especificidade da cultura contemporânea; isto é, um sujeito com formação para manejar criteriosamente as informações veiculadas no contexto em voga, objetivando torná-las conhecimentos intervenientes no delineamento de uma nova sociedade.

As escolas, por meio das ações do coordenador pedagógico, dentre outras, são convidadas a sistematizar, efetivar, de fato, a formação contínua do professor. A proba formação docente, no contexto escolar, deve ser favorecida e largamente difundida, visando à qualificação cultural, teórica e prática do professor, pois uma das arenas privilegiadas para que os professores materializem o diálogo, a troca de experiências, a sua própria formação, é a escola. Trata-se de uma formação que considera o potencial do professor, para que, além de apresentar uma postura crítica diante do contexto social em voga, produza conhecimentos e faça uso deles em benefício da sua própria formação. Da mesma forma, isso deve ocorrer em uma perspectiva diferenciada, uma vez que o professor é convidado a assumir o papel de promotor de uma "nova" prática pedagógica, em contraposição aos paradigmas tradicionais da educação, demarcados por uma ordem vertical de produção e difusão do conhecimento.

O resultado do processo supramencionado será uma prática pedagógica mais dialógica, envolvendo todos os sujeitos dos processos de ensino e aprendizagem. Para esses processos, um professor bem formado, em processo contínuo de formação, é de fundamental importância para aguçar e provocar um ambiente de diálogo e de crescimento crítico no tocante aos modos de aprender, ensinar e vivenciar o conhecimento apreendido, bem como para o despontamento de um "novo sujeito". Entretanto, o aludido processo de formação contínua do professor necessita ser avaliado periodicamente, em reuniões ou encontros pedagógicos, que contemplem a participação dos professores. Tal processo servirá como pilar para as mudanças que se fizerem necessárias. 
Em última instância, entre os pilares elencados neste corpo teórico, que devem sustentar a formação contínua docente, dar-se-á relevo a: orientação a respeito dos diversos elementos que compõem os processos de ensino e aprendizagem; espaços de avaliação das práticas pedagógicas sedimentadas no âmago da escola; formação para o exercício de uma prática fecunda e correlata com o contexto social vigente, isto é, convidar os professores a trabalharem pelo contínuo aperfeiçoamento dos conteúdos, dos métodos e práticas, a partir das quais os processos de ensino e aprendizagem se concretizam.

Cabe, ainda, salientar que, quando a formação contínua do professor é projetada a partir do contexto escolar, do fazer pedagógico do professor, esse contexto ganha caráter inovador, em outras palavras, quando formação docente caminha com a profissão, a prática pedagógica ganha nuance emblemática. Nessa estrutura, convém salientar que é preciso que todos os professores sejam arquitetos e, como tais, criem, transformem, façam diferente, não só no campo teórico, mas, principalmente, a partir da própria prática pedagógica, do exercício docente.

Em interface com todo o exposto, compreende-se que a formação contínua docente se constitui como pano de fundo para a transformação das práticas dos professores e, portanto, é o lugar do encontro, da acolhida, entre 0 professor e seus pares, assim como com o coordenador pedagógico. Entretanto, cada professor é responsável por seu processo de desenvolvimento profissional, direcionamento e discernimento de que caminhos percorrer na construção e reconstrução do conhecimento, descobertas e escolhas, o que se traduz na necessária formação contínua.

\section{“MARCHA À RÉ”: revisitando a discussão}

O sucesso de uma discussão é determinado também a partir das aprendizagens apreendidas e ideias ventiladas; isto é, a retomada das questões que nortearam a reflexão, assim como a apresentação das ideias consumatórias são elementos essenciais para a construção de novas práticas pelos professores e coordenadores pedagógicos, além de outros 
pesquisadores. Daí o que foi intitulado de "Marcha à ré", ou seja, revisitando a discussão.

Em suma, reitera-se aqui a escola como seara fértil para alojar a formação contínua do professor, entrincheirando-se de dinamismo e construção coletiva, pois o trabalho coletivo alarga a construção de saberes, o saber fazer, o saber ser, o compartilhar experiências, as dificuldades, 0 reconhecer falhas e o valorizar os avanços e as mudanças. E que a referida formação impulsione a reconstrução das práticas pedagógicas, conectadas a um processo formativo que lhe dê sentido e direção.

O contexto escolar precisa oportunizar espaço aos professores neste mundo em constante transformação, e isso exige formação contínua para eles, isto é, leva-se a cabo a proposição de uma formação contínua docente erguida com âncora nas práticas pedagógicas, saberes e experiências dos professores, enfim, a partir do âmbito escolar.

\section{Referências bibliográficas}

BRASIL. CONGRESSO NACIONAL. Lei de Diretrizes e Bases da Educação Nacional. Ldben 9.394/1996. Brasília: 2005. Disponível em: http://www2.senado.leg.br/bdsf/bitstream/handle/id/70320/65.pdf?sequence=3 Acesso em: 09 mar 2016.

BRASIL. CONGRESSO NACIONAL. Plano Nacional de Educação PNE. Brasília: $2014 . \quad$ Disponível em: http://www.observatoriodopne.org.br/uploads/reference/file/439/documentoreferencia.pdf Acesso em: 09 mar 2016.

CLEMENTI, N. A. A voz dos outros e a nossa voz. Alguns fatores que intervêm na atuação do coordenador. In: ALMEIDA, L. R. de; PLACCO, V. M. N. de. O coordenador pedagógico e o espaço de mudança. São Paulo: Edições Loyola, 2005. p. 53 a 66.

GARCIA, O. G. Pela ótica do PROVE, qual o lugar da coordenação pedagógica na formação do professor/professora na escola? . Revista Prove 10 anos, 1997-2007, p. 55-61, 2007. 